\title{
Analysis of the Relation between State of Health and Self-Discharge of Li-Ion Batteries
}

\section{Milán Attila Sőrés, Bálint Hartmann}

Department of Electric Power Engineering BME Faculty of Electrical Engineering and Informatics, Egry J. u. 18, 1111 Budapest, Hungary

sores.milan@vet.bme.hu, hartmann.balint@vet.bme.hu

Abstract: Li-ion batteries have become a widespread solution for modern energy storage systems, both for e-mobility and stationary storage. SOC and SOH estimation of batteries has great importance from both technical and economic aspects. There are many ways to estimate SOC and SOH with different complexity and accuracy rates, our paper focuses mostly on SOH. At first, this paper gives a brief review of possible methods of $\mathrm{SOH}$ determination. From these methods, one way is developed to measure an indicator related to $\mathrm{SOH}$, and from the indicator estimating it. In our paper, we analyzed the connection between $\mathrm{SOH}$ and self-discharge for different time periods. The capacity degradation was measured with a high current, that closely resembles modern e-mobility applications. After that, from our experimental data, with the measured self-discharge, the final best-estimated SOH value in the range of $\pm 3 \%$ is achieved.

Keywords: battery; Li-ion; state-of-health; self-discharge; degradation

\section{Introduction}

Nowadays, it is becoming a more and more important task to estimate battery cell SOC (state-of-charge) and SOH (state-of-health), both in e-mobility and stationary energy storage systems. The main focus of these is application dependent, though there are some basic criteria in accuracy, speed, and robustness. It is application dependent as in the case of SOC there are several electrochemical-based differential equations accurate enough, but they cannot be implemented on microcontrollers or FPGA due to their limited calculation capacity. There are simplified equations based on equivalent circuits or coulomb counting algorithms combining SOC estimation with other measurable quantities such as OCV (opencircuit voltage). However, some basic difficulties can be handled differently. First of all, there is the problem with the non-linearity of the SOC-OCV relationship that can be solved either by different methods, like the Kalman-filter-based method [1] or piecewise linear interpolation method [2]. An issue with these 
methods is that they may require information on the individual cell that is not available as manufacturers keep them as an industrial secret. From an economic point of view battery degradation cost shall be considered in the design phase of an energy storage system as shown in [3].

Battery health is usually connected with capacity fade and internal impedance increase, in the case of direct measurements. For capacity measurements, a precise current measuring device is required, as the SOC is an open-loop integral. In addition, the measurements shall be carried out with low current in terms of C-rate. Impedance measurements depend on the used battery model. One of the most complex ways is the electrochemical impedance spectroscopy (EIS) that gives the impedance values for a great range of frequencies [4]. In the case of a 2nd order, that was presented in [5] and used in many applications for example in [6]. Considering two $\mathrm{RC}$ branches the question is the determination of $\mathrm{R}_{0}, \mathrm{R}_{1}$, and $R_{2}$ ( $R_{1}$ and $R_{2}$ are sometimes named short and long referring to the time constant). In the advanced model, the hysteresis of these values is also considered, which means these values are dependent on the current direction (different resistance for charge and discharge). An indirect often used method is based on the investigation of OCV or pseudo-OCV curves. OCV is the no-load voltage of a battery, after a given relaxation period. This measurement takes time, therefore sometimes a socalled pseudo-OCV curve is used, constant current discharge with current below $\mathrm{C} / 25$. All these measurements require time and a proper testing device, for application the latter is sometimes not available, and in this case, the selfdischarge measurement could present an acceptable estimation of the $\mathrm{SOH}$.

This paper has the following structure, following the Introduction. In Section 2, State-of-Health Estimation, existing SOH estimation methods will be presented. Then in Section 3, Self-Discharge is presented, the authors present the most common literature concepts for self-discharge modeling and present a model for which the estimation will be applied. Following, in Section 4, Measurements experimental setup will be presented including the measurement devices and the selected cells and the measurement process will also be discussed. After this, in Section 5, the measurement results will be presented and evaluated in Section 6, the Measurement results. From the measurement results, a method for simplified capacity estimation will be discussed in the following Section 7, Estimation. Finally, Section 8, provides the Conclusions of our work, with the summarization of the measurements and all estimations.

\section{State-of-Health Estimation}

There are several possibilities for SOH estimation. In most cases, SOH decrease is connected to either the loss of available capacity or increasing internal impedance (especially in equivalent circuits). Most information comes from the post-mortem 
analysis of a battery cell [7]. In their analysis, D. Aurbach et. al examined a 18650 -size cell from LG chem, with around $1800 \mathrm{mAh}$ capacity [8]. They cycled the cells at two different temperatures $\left(25^{\circ} \mathrm{C}\right.$ and $\left.40^{\circ} \mathrm{C}\right)$ for about 250 and 300 cycles, respectively. At $25^{\circ} \mathrm{C}$ the cells reached $80 \%$ of their capacity after $230-250$ cycles, while at $40^{\circ} \mathrm{C}$ experiments $140-160$ cycles according to their results. They observed both the anode and cathodes with SEM (scanning electron microscope) and compared the Nyquist plots of EIS measurements. Four possible reasons were presented for capacity fading: degradation of active mass on the anode; degradation of the solution; degradation of active mass on the cathode; reactions on the surfaces of both electrodes elevating their impedance, hence increasing the impedance of the whole battery cell. Waldmann et. al [9] examined 18650-size $\mathrm{NCA} /$ graphite cells with a wider temperature range. Their experiments were conducted at $0^{\circ} \mathrm{C}, 5^{\circ} \mathrm{C}, 25^{\circ} \mathrm{C}$, and $45^{\circ} \mathrm{C}$. In their study, they recorded the voltage relaxation for 4 hours from the end of the charge. Their discharge method for the $3250 \mathrm{mAh}$ capacity cells used a relatively small discharge current, $0.5 \mathrm{C}$. They find that at low temperatures $\left(0^{\circ} \mathrm{C}\right)$ the main aging factor is Li plating, while at higher temperatures $\left(45^{\circ} \mathrm{C}\right)$ it is related to SEI growth and adhesive loss of active material. In [10] the authors give a review on calendar aging mechanisms of different cell chemistries. In their paper, they compared calendar capacity loss and resistance increase of the different cell chemistries at different SOC levels and temperatures. Results show that different ambient temperature and SOC level has different effects on different cell types. As an example, for their paper, an LCO chemistry cell tolerates high temperatures from a calendar capacity fade point of view around $80 \%$ SOC level. On the contrary with $80 \%$ maximum SOC a bigger battery would be required for the same energy or performance. That would mean a serious disadvantage in applications where mass or volume limitations are present for example an aircraft. Unfortunately, post mortem analysis can give details only after the cell died. For similar reasons, other invasive methods cannot be applied as well. For non-invasive methods, there are two major categories either based on voltage signal or non-voltage signals. Voltage signal-based measurement methods typically use OCV, impedance, electrochemical parameters. Other non-voltage signal-based methods are temperature, ultrasound, and force measurement [11]. In [12] authors used a resistance-based two-tier DC load pattern, and a discharge and relaxation method for $\mathrm{OCV}$, and an equivalent circuit real-time estimation method. The discharge phase lasted for one hour, while the relaxation was chosen to be two hours. In their experiments, Lüders et al. [13] has already examined the relation of Li plating and voltage relaxation curves. As indicated previously the $\mathrm{Li}$ plating occurs at low temperatures, therefore their experiments were performed at $-2^{\circ} \mathrm{C}$. For discharge they used low discharge rates for standard CC-CV (constant current-constant voltage) charge varied from 0.05 to $1 \mathrm{C}$. Voltage relaxation in their measurements was recorded continuously for 4 hours. The main goal in selected papers was to show the main factors affecting the battery $\mathrm{SOH}$, and the methods that help in its estimation. There is another possibility used in measuring 
$\mathrm{SOH}$, it is based on the voltage change during discharge, Differential Voltage Analysis, used in [14] to give a mathematical model for health decrease.

Usually, in the previously mentioned methods, the basic concept is to find a measurable quantity that is closely related to the degradation of the battery. In this paper, we observed the self-discharge of a chosen cell that undergoes continuous capacity fade during the first half of the cell lifetime. Capacity fade is reached on one hand with high C-rate discharge [15] and on the other hand with charging and storing the cell around $4.2 \mathrm{~V}(\sim 100 \%$ SOC) [16]. In our measurement, we chose a cell that can be used in e-mobility applications, as there is a need for higher C-rate discharge in these applications. In their review, Barré et. al [17] compare battery aging estimation methods, based on five main aspects (adaptation, precision, operation without data, real-time application, and prediction). The compared methods: direct measurement; equivalent circuit method; electrochemical model; performance models; analytical model and statistical method. From their comparison, direct measurement is the best at adaptation and precision, while in real-time application and prediction is the worst. From the already developed methods, electrochemical models are the most precise, though their adaptation is rather challenging. Statistical methods are the easiest to adapt, while cannot operate without data. The other methods are between these highlighted ones. During the presented measurements, the capacity was directly measured for comparison with the estimated values. In our experiments, we analyzed the connection between self-discharge and capacity fade. With the presented method a new $\mathrm{SOH}$ indicating factor is presented, that can be used both for individual cell $\mathrm{SOH}$ estimation and estimation of battery packs or swappable battery modules.

\section{Self-Discharge}

The self-discharge phenomenon is present for all types of batteries such as leadacid, Ni-MH, and of course for Li-ion. As our measurements were performed with Li-ion cells, their self-discharge will be discussed in short. The mechanism is related to SOC, electrochemistry, electrolyte, chemical reactions, and temperature [18]. From the internal reactions point of view, it is strongly related to the socalled SEI formation [19].

This SEI layer consumes intercalated Lithium both during charge-discharge reactions and self-discharge [20]. SEI formation is in connection with irreversible capacity loss as well. Beyond of SEI layer, in [21] it was discussed how the electrolyte can contribute to self-discharge in the case of a solution of LiPF6 in linear and cyclic carbonates. Besides the reactions of the electrolyte, there are several processes causing self-discharge as well. Reactions such as internal electron leakage, dissolution of active electrode materials, corrosion of current collectors, and parasitic electrochemical reactions on the electrode surface 
according to [22]. For simulation of self-discharge, there are semi-empirical models developed based usually on the Butler-Volmer equation and Nernst equation, as presented in the overview on the self-discharge topic of the authors [23]. From those methods, the one developed by Galushkin et al. [24] and adapted to Li-ion batteries by Deutschen et. al. [25] is used for estimation. They derived two equations for approximate voltage decay one for short term (1), and one for long term (3), with switching from short term to long term around the $25^{\text {th }}$ day.

$$
V_{t}(t)=V_{t, 0}-\frac{1}{b} \cdot \ln \left(1+\frac{I_{0} \cdot b \cdot \exp \left(b \cdot V_{0}\right)-1}{C} t\right)
$$

This short equation is formally very similar to the so-called Nernst equation [26]. It has five parameters, from which $b$ can be further expressed (2).

$$
b=\frac{z F}{R T}
$$

For Li-ion cells $z=1$ (as the number of electrons involved in the electrode reaction [26]), $F$ is the Faraday constant, $R$ is the gas constant, and $T$ is the absolute temperature. From (2) it is obvious that $V_{t}$ depends on temperature as well, and with knowledge of the temperature value $b$ can be calculated.

$$
V_{t}(t)=V_{t, \infty}+\frac{1-\exp \left(-b \cdot V_{0}\right)}{b} \exp \left(-\frac{I_{0} \cdot b}{C} \cdot t\right)
$$

Long-term approximation (3) has similar parameters, the difference is that in (1) an initial voltage is given, while here a stationary voltage is used.

\section{Measurements}

In this section, the measurement setup, chosen cell, self-discharge phenomenon, and the measurement process are presented. Since the aim of the measurements was to observe the degradation of the chosen battery cells that can be used in e-mobility applications. For this purpose, the cells were discharged with a high constant current rate (4C) as e-mobility applications like electrical aviation requires quite high discharge rates, opposing stationary storage systems, where the load can be rather low [27]. The selected current rate will be further explained in Subsection 2.1 selected cells. 


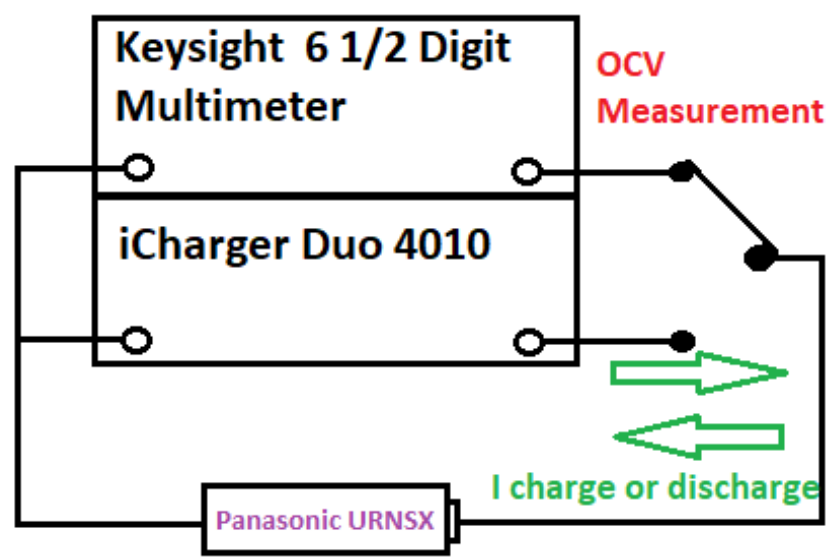

Figure 1

Schematic diagram of the test setup

Figure 1 shows the measurement setup schematic. The tested cells are connected to the iCharger Duo 4010 device for charging and discharging. As the iCharger is capable of voltage measurement as well the digital multimeter is not used during this phase. For open-circuit voltage (OCV) only the $6 \frac{1}{2} 2$ digit Keysight multimeter was used, as it provides more precise values. During the measurements, ambient conditions are recorded as well (e.g. temperature). The list of the equipment can be found in Table 1 .

Table 1

Devices used in the measurement

\begin{tabular}{|c|c|}
\hline Device & Measurement type \\
\hline Keysight 34461A (6 $1 / 2$ digit multimeter) & OCV \\
\hline Junsi iCharger Duo 4010 & Charge and Discharge voltage and current \\
\hline Testo 622 (Scientific Ambient Monitor) & Ambient conditions \\
\hline
\end{tabular}

\subsection{Selected Cells}

The selected cells for the measurements were Panasonic UR18650NSX type [28]. These are cylindrical 18650 size cells with a 2.5 Ah rated capacity. According to its datasheet, a cell can be discharged with continuous $10 \mathrm{C}$, that is $25 \mathrm{~A}$, tough around $20 \%$ of SOC the battery temperature reaches $80^{\circ} \mathrm{C}$. That is why a $10 \mathrm{C}$ discharge rate may not be preferable for e-mobility applications, while in the range of a bit smaller discharge rate $(8 \mathrm{C})$ the cell temperature remains below $80{ }^{\circ} \mathrm{C}$. In our test method, $4 \mathrm{C}$ constant current discharge was selected, as it is still a high current value $(10 \mathrm{~A})$ and the cell delivers performance as well. Beyond power and energy considerations it is also an important factor that the temperature of the cells remains certainly at an acceptable level. The manufacturer provides 
information on the cyclic performance of the battery cell with $4 \mathrm{C}$ and $10 \mathrm{C}$ discharge rates. In the first case, the cells reach $80 \%$ of their initial capacity during 300 cycles, while in the second case during 200 cycles. This also means that a higher discharge rate has a negative effect on the cycle life of a cell. The reason for choosing this cell is the possibility of high discharge rates that is essential for e-mobility applications where the required performance can be very high. Another aspect of the selection was the relatively high energy density of the cell, approximately $204 \mathrm{Wh} / \mathrm{kg}$ gravimetric and $514 \mathrm{Wh} / \mathrm{l}$ in volumetric means according to the datasheet.

\subsection{Measurement Process}

These measurements aimed to examine the effects of this high current discharge on the self-discharge of the cells. Therefore, the open-circuit voltage (OCV) was measured $10 \mathrm{~min}, 24 \mathrm{~h}, 48 \mathrm{~h}$, and one week after fully charging the cells. The 10minute measurements were done after each charging, but for obvious time limitations, the other three ( $24 \mathrm{~h}, 48 \mathrm{~h}$, and one week) were done only after 10 cycles. After charging the cell the voltage decreases relatively fast, due to polarization, a 10-minute relaxation time was chosen for OCV measurements similar to [29], where the authors used from 6 minutes to 5 hours relaxation times. In [30] the authors find that the steady-state is reached in the range of $24 \mathrm{~h}$. In the presented measurements one cycle means one full discharge and recharge.

Altogether 5 Panasonic URNSX cells were tested. Originally there were 6 cells but after 35 cycles of testing, one of them had to be terminated due to some mechanical damage. The mechanical problem was independent of the test procedure. Altogether 100 full cycles were done.

The test contained three major parts:

- Charging the cells to $100 \%$ SOC (CC-CV)

- Relaxation

- Discharging with $4 \mathrm{C}$ until 2.65V (CC)

During the initial phase, before the first discharge, of the test, cells were charged to maximum SOC, and for a week. During this initial relaxation period, the OCV of the cell was measured after $10 \mathrm{~min}, 24 \mathrm{~h}, 48 \mathrm{~h}$, and a week. Then another charging started to compensate for the slight capacity loss due to self-discharge. The next step was the discharge with $4 \mathrm{C}$, after that charging again and relaxation for $10 \mathrm{~min}$, and OCV measurement. These were repeated 10 times, that is 10 cycles altogether. After the tenth cycle, a longer relaxation period started for a week, measuring voltage the same way in the initial phase. The charging step was performed according to $\mathrm{CC}-\mathrm{CV}$ protocol, wherein $\mathrm{CC}$ phase $1 \mathrm{C}(2.5 \mathrm{~A})$ was used. In the $\mathrm{CV}$ phase the target voltage was $4.2 \mathrm{~V}$. In cases of charge after the relaxing period, only the $\mathrm{CV}$ phase was performed. For discharge, as mentioned 
previously, a 4C constant current was used with cut-off voltage $2.65 \mathrm{~V}$ as a safety limit as opposed to the $2.5 \mathrm{~V}$. During the discharge phase cell voltage [V], current $[\mathrm{A}]$, and relative time [s] were recoded, while capacity [mAh], power [W], and energy [Wh] were calculated from them. During each test step, ambient conditions were recorded. These are: temperature $\left[{ }^{\circ} \mathrm{C}\right]$, relative humidity $[\%]$ and air pressure [hPa].

\section{Measurement Results}

\subsection{Capacity Measurement}

During the capacity measurements, the original six cells were cycled. They were labeled from S10 to S15. Measurements of S14 were terminated, due to some mechanical damage, not related to the charge-discharge cycles. In this section, some graphs from the discharge measurements are shown. Capacity was calculated by the Coulomb counting (or Amper counting) method. The method is described by (4) based on [31]:

$$
S O C=S O C_{0}-\frac{1}{Q_{r}} \cdot \int_{t_{0}}^{t} \eta I(\tau) d \tau
$$

According to (4) the state of charge consists of two parts $\mathrm{SOC}_{0}$, the initial SOC (in the presented case always $100 \%$ at the start of discharge. The other term is an integral of the charge or discharges current between the initial time $t_{0}$ and $t$. As SOC is a percentage the result of the integration is divided by the term $\mathrm{Q}_{\mathrm{r}}$, the rated capacity from the datasheet. Since the capacity of a new cell usually differs from $\mathrm{Q}_{\mathrm{r}}$, because of different ambient conditions for example; and in our measurement, the used discharge was not the datasheet specified method (not measured at $20{ }^{\circ} \mathrm{C}$ ) therefore the initial capacity was used through the whole measurement. The constant $\eta$ is called the coulombic efficiency, for Li-ion batteries, it is very close to 1 [32], therefore it is considered to be constant 1 . In this paper the capacity of the cell is denoted by Q, to avoid any confusion with the current rate $\mathrm{C}$.

Fig. 2 shows the voltage of one battery cell during 4C constant current discharge during the first 20 cycles. The voltage maximum during charge was set to $4.2 \mathrm{~V}$, the initial voltage at the start, after 10 minutes relax, was between $4.189 \mathrm{~V}$ and $4.178 \mathrm{~V}$ depending mostly on the ambient temperature. The cut-off voltage was set to $2.65 \mathrm{~V}$ during all discharge cases to ensure a safer operation and not to reach deep discharge accidentally. In practice under about $3 \mathrm{~V}$ with load, the cell voltage drops more and more fast. At this range, the remaining capacity is relatively small, 
while the temperature increases fast. This temperature rise can be explained by the increasing serial resistance at low SOC values from the equivalent circuit point of view. From Fig. 2 it can be seen that at the first 20 cycles the cell performance slightly decreased, as at the first cycles the discharge took about 830 seconds, while at the end of the sequence it took only 820 seconds. The nominal time for $4 \mathrm{C}$ discharge would be 900 secs or 15 minutes. The difference from the ideal quarter-hour measurement time, is probably because the voltage did not reach 2.5 $\mathrm{V}$ and the cells themselves have some difference from catalog values.

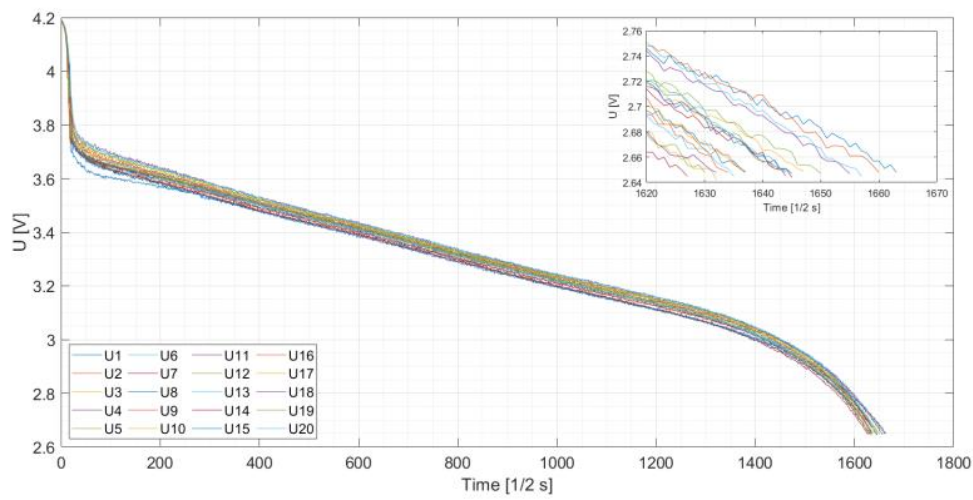

Figure 2

Voltage vs. time of one cell during the first 20 cycles

On the aging of the cells, not the first 20 cycles would give information but all the cycles. Since the one-week relaxation occurred only after 10 cycles, therefore, the measurements after these relaxation periods are shown in Fig. 3.

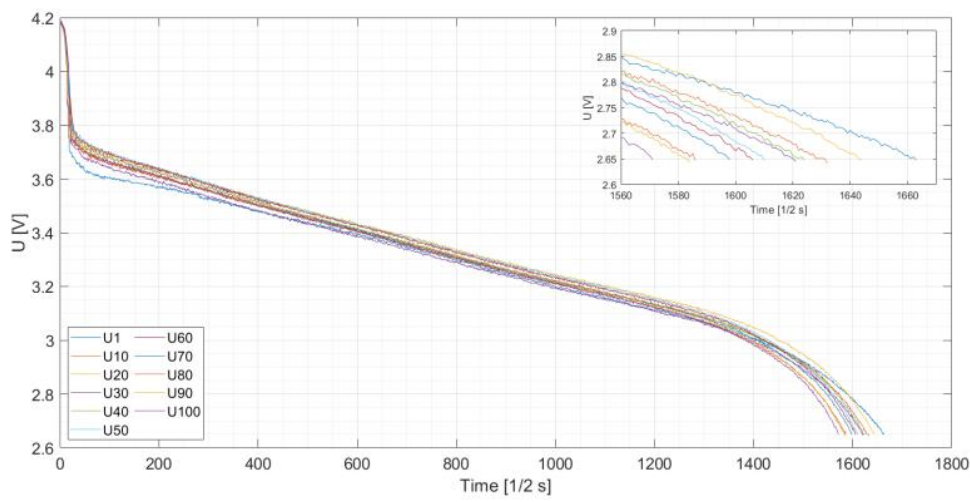

Figure 3

Cell Voltage of one cell during cycling, only every $10^{\text {th }}$ cycle presented 
Voltages at end of the measurement, only the last 150 seconds, are shown in the upper right corner of Fig. 3 as well. It shows that at the first cycle, with fresh cells the discharge took the most time, from $10^{\text {th }}$ to $40^{\text {th }}$ the time is very similar to each other. From the $50^{\text {th }}$, the second half of our tests it monotonously shortens from around 810 seconds to 785 seconds.

Figure 4 shows the measured capacity in percentage of all the five cells and their average value (red line). The capacity should monotously decrease with cycling, but in Fig. 4 there are some local minimums, after which capacity seems to be growing a bit. These are because of the so-called overhang effect discussed in depth in [33] and [34]. Briefly, as the anode is designed to be slightly wider than the cathode, some Li atoms can diffuse to this region in case of longer storage periods. The apparent capacity loss is slowly reversible with cycling, that is the reason of this curve. The overhang effect is significant in higher SOC ranges.

For simplification reasons, the measured capacity of the first discharge measurement is considered to be $100 \%$. From Fig. 4 and Fig. 5 it can be seen that during the first 15-20 cycles capacity fade has a higher slope after that the slope decreases and becomes almost constant until the $100^{\text {th }}$ cycle. As the five cells follow a very similar pattern in Fig. 5 only the average relative SOC decrease will be presented with a linear approximation of their slope. The yellow line is the approximation of the slope of the first 15 cycles the orange line is the remaining 85 cycles. Their equation is presented on the diagram; their color is respective to the line color. From the equations it can be stated that the slope of the first 15 capacity results is almost 3 times bigger, in absolute value $(0.159$ [\% / cycle]), than the measurements after that $(0.57$ [\% / cycles] $)$.

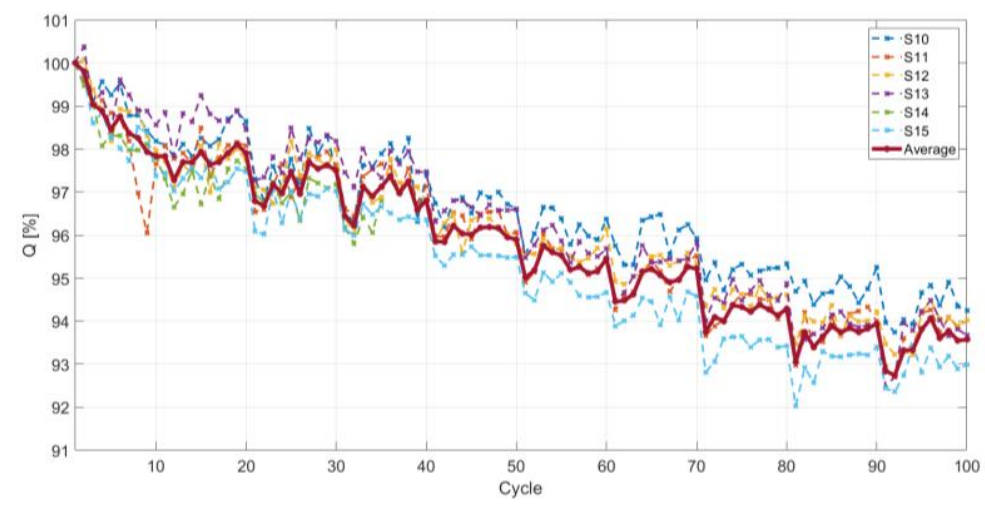

Figure 4

Relative capacity of the cells 


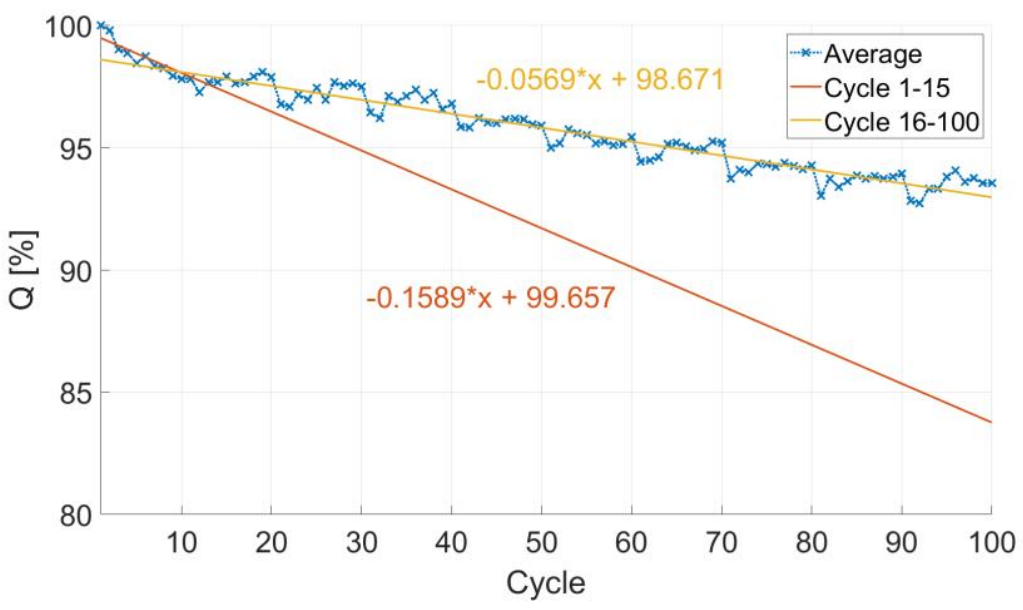

Figure 5

Slope of capacity decrease (first 15 cycles yellow; last 85 orange)

If we neglect the rapid capacity decrease during the few cycles in the beginning it is possible to fit a linear curve to the measured values shown in Figs. 5 and 6. The orange curve was created with the MATLAB curve fitting tool, and the average measured values. The fitting algorithm was set to Linear-Least Squares. The equation of the curve is in Eq. 2.

$$
Q(c y c)=q_{d} \cdot c y c+q_{0}
$$

In Eq. $2 \mathrm{Q}$ is the capacity, $c y c$ is the cycle number, $q_{d}$ (capacity decrease) and $q_{0}$ (initial capacity) are coefficients with values $-0.0569,98.67$ respectively, with $95 \%$ confidence bounds.

\subsection{OCV Measurement}

In this section, the results of the OCV measurements will be presented. As described in section 2.3. the $24 \mathrm{~h}, 48 \mathrm{~h}$, and 1-week measurements were done only after 10 cycles, therefore only 10 measurements results are shown in Fig. 6 . For simplification reasons, only the average of the cell voltages will be presented. In addition to the measured values, a linear trendline is presented as well. The trendline was created with MS Excel's built-in function. The measured voltages at $30^{\text {th }}$ and $70^{\text {th }}$ cycles were rather outlier values, probably because of some errors. Therefore, they are omitted in the following estimation methods. 


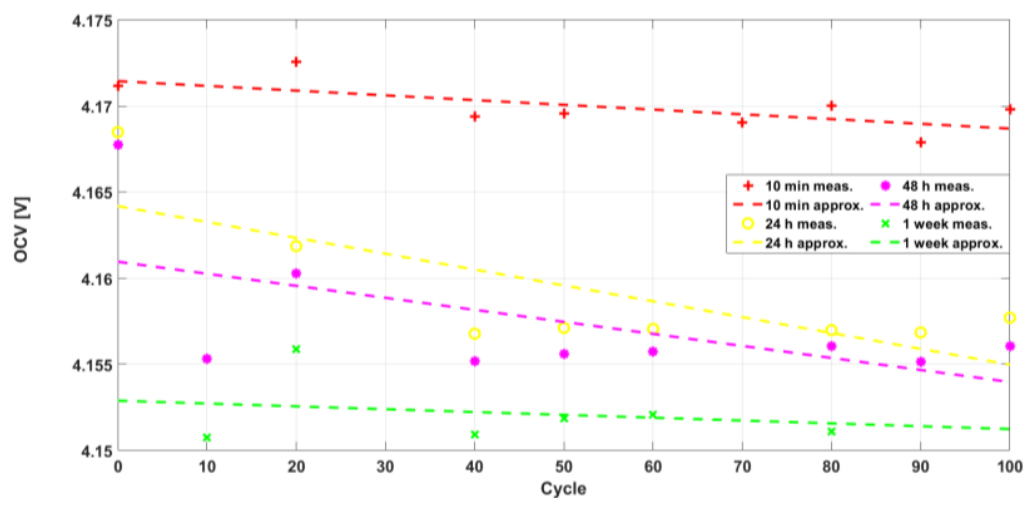

Figure 6

Measured OCV after different relaxation times

It can be seen from the figures that the measured voltages have a decreasing tendency, as expected. The red plus signs and dashed trendline belong to the 10minute measurements, the yellow circles, and the dashed trendline to the 24-hour relaxation times. Magenta stars and green crosses and dashed linear trendlines belong to the 48 hours and one-week relaxation, respectively. If we compare the diagrams it can be stated that the slope decreases with the relaxation time for $24 \mathrm{~h}$, $48 \mathrm{~h}$, and 1-week OCV data, for 10 min measurements there is a negative slope as well, but it is more similar to the 1 -week measurements than to the $24 \mathrm{~h}$ or $48 \mathrm{~h}$. The voltage decrease values are summarized in Table 2 .

Table 2

Voltage decrease after specified relaxation time

\begin{tabular}{|c|c|c|}
\hline Relaxation Period & $\mathbf{v}_{\mathbf{d}}[\boldsymbol{\mu} \mathbf{V} / \mathbf{c y c l e}]$ & $\mathbf{v}_{\mathbf{0}}[\mathbf{V}]$ \\
\hline 10 minutes & -27.54 & 4.171 \\
\hline 24 hours & -92.11 & 4.164 \\
\hline 48 hours & -69.84 & 4.161 \\
\hline 1 week & -16.47 & 4.153 \\
\hline
\end{tabular}

\section{Estimation}

In the previous section, it is presented that both capacity and open-circuit voltages tend to decrease with cycling. For the voltages, the decrease is different for different relaxation times. This section aims to observe the estimation results for a capacity fade with the help of different voltages. As shown in Fig. 6 the decrease of the average measured capacity values is around $0.057 \%$ (relative to the first capacity measurement) per cycle. This information is not available generally, only 
after long battery cycling processes. On the other hand, manufacturers usually provide some information on cycling characteristics for the battery cell, that can be used for estimation. This is shown in Fig. 7.

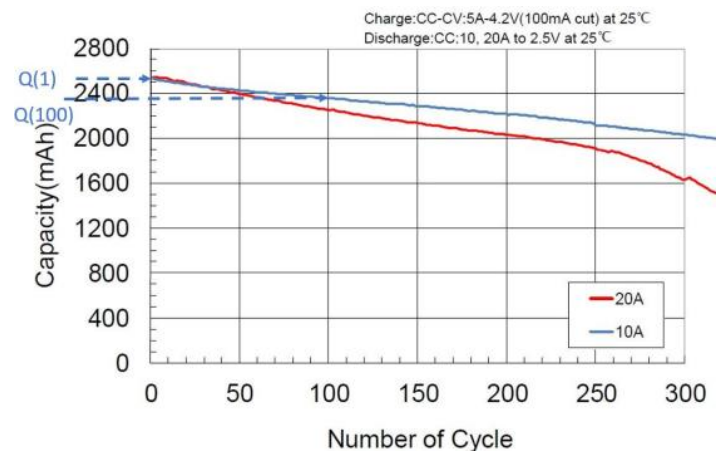

Figure 7

Cycling characteristics of the Panasonic UR18650NSX cell [28]

The manufacturer in this case gave two cycling curves for two different discharge currents. Blue is for $10 \mathrm{~A}$ discharge current, which corresponds to $4 \mathrm{C}$, and red curve for $20 \mathrm{~A}$ that corresponds to $8 \mathrm{C}$. As our measurements are concluded with $4 \mathrm{C}$, the blue curve is used. From the datasheet curves $\mathrm{Q}(1)$, as the initial capacity of the cell and Q(100), capacity after 100 cycles are used. As another point for linear estimation $\mathrm{Q}(100)$ is chosen as our measurements lasted only for 100 cycles. From Fig. $7 \mathrm{Q}(1)$ is $2510 \mathrm{mAh}, \mathrm{Q}(100)$ is $2360 \mathrm{mAh}$. Capacity decrease is around $150 \mathrm{mAh}$ for 100 cycles, the $\mathrm{q}_{\mathrm{d}}$ value become $0.06 \%$ / cyc. This value aligns with the measured discharge rate quite well.

Voltage decrease will be estimated based on Eq. 1. As previously mentioned the equation has two independent variables $t$ and $T$. This would lead to a surface fitting problem. Unfortunately, the measured temperature values are from a very narrow range. The minimum temperature was $23.5^{\circ} \mathrm{C}$, the maximum was $26.6^{\circ} \mathrm{C}$. In terms of $b$, the minimum would be 38.7 the max would be 39.1. That would give questionable results regarding surface fitting. Therefore, instead of using individual $T$ values for the fitting, the average will be used, it is $25.5^{\circ} \mathrm{C}$. With this approximation Eq. 1. will be simplified in a way that it contains only two parameters shown in Eq. 5.

$$
V_{t}(t)=V_{t, 0}-\frac{1}{b} \cdot(1+p t)
$$

Note that $V_{t, 0}$ is not changed, $b$ is constant, and $p$ incorporates the original parameters $I_{0}, V_{0}$ and, $C$. Simplification was necessary because the original equation continued four parameters (considering $b$ constant). The measured voltages after 10 minutes, 24 hours, 48 hours and, 1-week would make it possible 
to fit the original curve, however, the 10 -minute voltage measurement has to be excluded from the curve fitting, as it is not part of the self-discharge period, but the relaxation after current flow. From an equivalent circuit method point of view, only the terminal voltage $\left(V_{t}\right)$ can be measured without disassembling the cell.

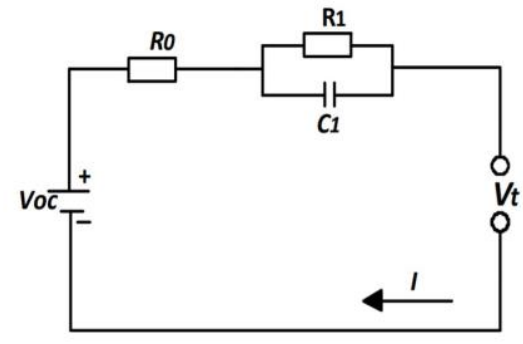

Figure 8

Li-ion battery model with one RC branch [35]

That means measured $V t$ has two terms, open-circuit voltage, and the voltage of the R1-C1 parallel term. This voltage decreases to zero in time, according to their time constant. A similar idea applies in the case of more parallel RC branches. The time these voltages are negligible depends on the model, can last from minutes to several hours [36].

For estimation and validation the measured cells are split into two sets. Parameter estimation was performed on the first set: S10, S11, S12 cells. These cells are referred as estimation set. The validation was performed on the second set: S13, S14 and S15. Unfortunately, S14 was withdrawn from the measurements, as previously mentioned. These cells are referred as validation set.

With MATLAB Curve Fitting Toolbox, parameters $V_{t, 0}$ and $p$ were fit to the measured voltage points. Table 2 shows the parameters, R-square and, RMSE values.

Table 2

Curve fitting results

\begin{tabular}{|c|c|c|c|c|}
\hline & $\mathbf{V}_{\mathbf{t}, \mathbf{0}}$ & $\mathbf{p}$ & $\mathbf{R}^{\mathbf{2}}$ & $\mathbf{R M S E}$ \\
\hline 10 & 4.158 & 0.001722 & 1 & - \\
\hline 20 & 4.16 & 0.001722 & 0.9893 & 0.000430 \\
\hline 40 & 4.159 & 0.001825 & 0.9889 & 0.000461 \\
\hline 50 & 4.159 & 0.001582 & 0.9885 & 0.000414 \\
\hline 60 & 4.16 & 0.001517 & 0.9983 & 0.000151 \\
\hline 80 & 4.1595 & 0.001377 & 0.9391 & 0.000687 \\
\hline 90 & 4.159 & 0.001467 & 0.9659 & 0.000675 \\
\hline
\end{tabular}


The estimation result shows, that $V t, 0$ remains constant, while parameter $p$ shows a clear decrease. The $1^{\text {st }}$ measurement is omitted because previous results in Fig. 5 shows that the capacity fade becomes steady between cycle number 10 and 20 . For the $100^{\text {th }}$ cycle, the voltage result measurement file was damaged therefore, these values are omitted as well. A similar $\mathrm{p}$ estimation was performed for the validation set as well.

Fig. 9 shows the estimated values for $\mathrm{p}$, and a linear trendline is fitted to these values. The slope of the trendline is $-4.54 \cdot 10^{-6}\left(p_{d}\right)$ and the offset is $1.829 \cdot 10^{-3}$. These $p$ values decline similar to the decline of measured capacity, so the slope of the trendline for $p_{d}$ and slope of the capacity $q_{d}$ from the estimation set will be used to estimate capacity fade Eq. 6 .

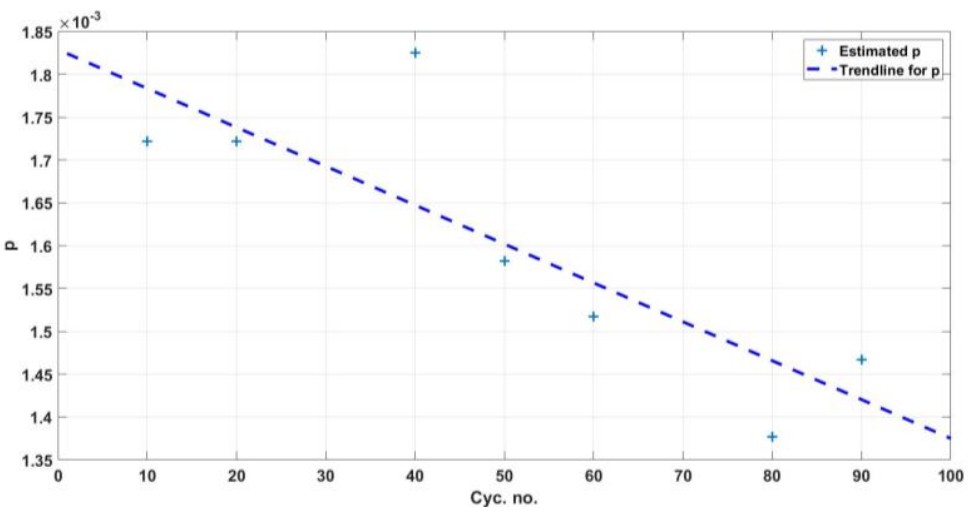

Figure 9

Results of estimating parameter $\mathrm{p}$ and trendline fitted to it

Index $v$ in Eq. 6 refers to values from the validation set of cells and the init index is the $10^{\text {th }}$ measured value, or fitted in case of $p$.

$$
Q_{v}(c y c)=Q_{v, \text { init }}-\frac{q_{d}}{p_{d}} \cdot\left[p_{v, \text { init }}-p_{v}(c y c)\right]
$$

Note that there were only ten voltage measurements for each period, so for $\mathrm{p}_{\mathrm{v}}(\mathrm{cyc})$, linear interpolation was applied on the measured data.

\section{Estimation Results}

Fig. 10 shows the original capacity vs. cycles curve and the estimated capacity curves.

In Fig. 10 the blue points are the measured capacity values of the validation set, the red ones are the estimated capacity values based on Eq. 6 . 


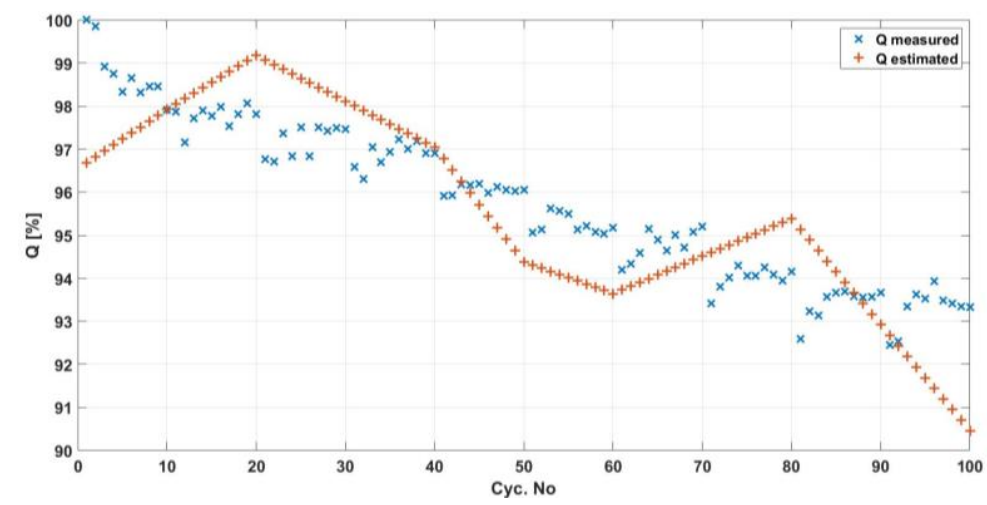

Figure 10

Measured and estimated capacity

\section{Estimation Accuracy}

The accuracy of the measurement is presented in Fig. 11. Here the percentage error is calculated by Eq. 7 for the $\mathrm{n}^{\text {th }}$ cycle.

$$
\operatorname{Error}(n)=\frac{Q_{\text {measured }}(n)-Q_{\text {estimated }}(n)}{Q_{\text {measured }}(n)} \cdot 100
$$

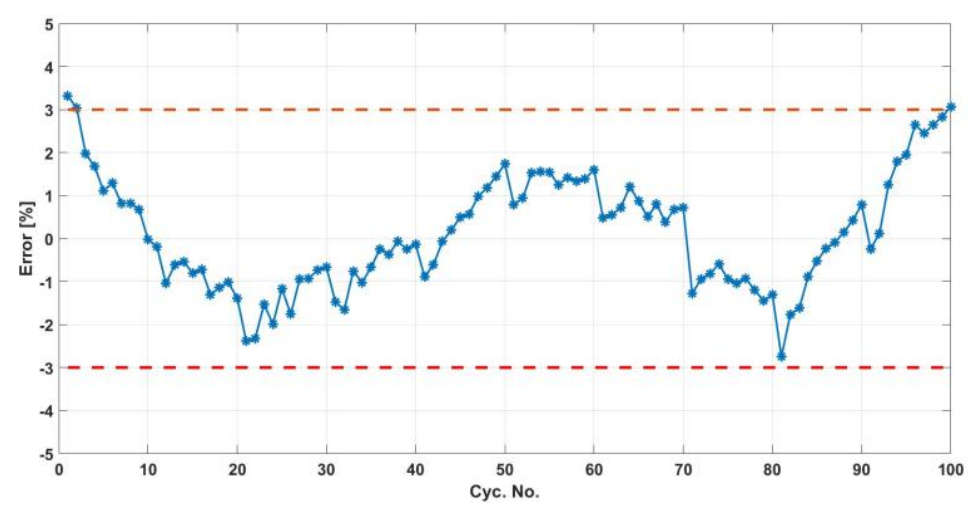

Figure 11

Relative error of the estimated capacities

In. Fig. 11 it is shown that the relative error of the estimation remains in the range of $\pm 3 \%$ for the relevant cycles. Although previously mentioned that the first 10 measurement results were excluded from the estimation process, their estimation result is presented as well in this figure. 


\section{Conclusions}

In this paper, the authors presented a link between cell SOH (capacity decrease) and the self-discharge process of a chosen Li-ion battery cell, suitable for emobility applications. The measurement results involved the first hundred cycles of five cells with a relatively high discharge rate. The main purpose of these tests was to analyze the effects of this high current discharge on the self-discharge of the cells.

Although effects of self-discharge are considered to be smaller for Li-ion technology, the voltage decrease was measurable. Open circuit cell voltage was measured four times after charging was finished: 10 minutes, 24 hours, 48 hours, and one week. A previously developed self-discharge model was applied to investigate aging-related issues. Although a relatively simple estimation method was used for calculating $\mathrm{SOH}$, results show that it can give fairly accurate results. This can be used on battery modules, that are allowed to have a resting period, for example in electric vehicles. All capacity and open circuit voltage measurement data is accessible [37].

\section{References}

[1] L. Lavigne, J. Sabatier, J. Mbala Francisco, F. Guillemard, A. Noury: Lithium-ion Open Circuit Voltage (OCV) curve modelling and its ageing adjustment. Journal of Power Sources 324 (2016) 694-703

[2] I. Baccouche, S. Jemmali, A. Mlayah, B. Manai, N. E. B. Amara: Implementation of an Improved Coulomb-Counting Algorithm Based on a Piecewise SOC-OCV Relationship for SOC Estimation of Li-Ion Battery. International Journal of Renewable Energy Research. Vol. 8, No. 1, pp. 178-187, 2018

[3] O. Boqtob, H. El Moussaoui, H. El Markhi and T. Lamhamdi: Energy Scheduling of Isolated Microgrid with Battery Degradation Cost using Hybrid Particle Swarm Optimization with Sine Cosine Acceleration Coefficients. International Journal of Renewable Energy Research. Vol. 10, No. 2, pp. 704-715, 2020

[4] T. Stockley, K. Thanapalan, M. Bowkett, J. Williams, M. Hathway: Advanced EIS Techniques for Performance Evaluation of Li-ion Cells. Proceedings of the $19^{\text {th }}$ World Congress The International Federation of Automatic Control Cape Town, South Africa. August 24-29, 2014

[5] Chen, M., Rincón-Mora, G. A: “Accurate Electrical Battery Model Capable of Predicting Runtime and I-V performance", IEEE Transactions on energy conversion, Vol. 21, No. 2, 2006, pp. 504-511

[6] T. Debreceni, G. Gy. Balázs, I. Varjasi: Mission Profile-Oriented Design of Battery Systems for Electric Vehicles in MATLAB/Simulink. International Conference on Renewable Energies and Power Quality (ICREPQ'16) 
[7] A. Friesen, X. Mönnighoff, M. Börner, J. Haetge, F. M. Schappacher, M. Winter: Influence of temperature on the aging behavior of 18650-type lithium ion cells: A comprehensive approach combining electrochemical characterization and post-mortem-analysis. Journal of Power Sources 342 (2017) pp. 88-97, http://dx.doi.org/10.1016/j.jpowsour.2016.12.040

[8] D. Aurbach, B. Markovsky, A. Rodkin, M. Cojocaru, E. Levi a, H.-J. Kim: An analysis of rechargeable lithium-ion batteries after prolonged cycling. Electrochimica Acta 00 (2002) pp. 1-13

[9] T. Waldmann, J. B. Quinn, K. Richter, M. Kasper, A. Tost, A. Klein, M. Wohlfahrt-Mehrens: Electrochemical, Post-Mortem, and ARC Analysis of Li-Ion CellSafety in Second-Life Applications. Journal of The Electrochemical Society, 164 (13) pp. 3154-3162 (2017)

[10] M. Dubarry, N. Qin, P. Brooker: Calendar aging of commercial Li-ion cells of different chemistries - A review. Current Opinion in Electrochemistry Vol. 9, pp. 106-113, 2018

[11] J. Tian, R. Xiong, W. Shen: A review on state of health estimation for lithium ion batteries in photovoltaic systems. eTransportation 2 (2019) 100028, https://doi.org/10.1016/j.etran.2019.100028

[12] Venkatesh Prasad K. S., B. P. Divakar: Real Time Estimation of SoC and $\mathrm{SoH}$ of Batteries. International Journal of Renewable Energy Research. Vol. 8, No. 1, pp. 44-55, 2018

[13] C. von Lüders, V. Zinth, S. V. Erharda, P. J. Osswalda, M. Hofmann, R. Gilles, A. Jossen: Lithium plating in lithium-ion batteries investigated by voltagerelaxation and in situ neutron diffraction. Journal of Power Sources, Vol. 342, pp. 17-23, 2017, http://dx.doi.org/10.1016/j.jpowsour. 2016.12.032

[14] J. Wang, J. Purewal, P. Liu, J. Hicks-Garner, S. Soukazian, E. Sherman, A. Sorenson, L. Vu, H. Tataria, M. W. Verbrugge: Degradation of lithium ion batteries employing graphite negatives andnickelecobaltemanganese oxidepspinel manganese oxide positives:Part 1, aging mechanisms and life estimation. Journal of Power Sources Vol. 269, pp. 937-948, 2014

[15] G. Ning, B. Haran, B. N. Popov: Capacity fade study of lithium-ion batteries cycled at high discharge rates. Journal of Power Sources 117 (2003) pp. 160-169, doi:10.1016/S0378-7753(03)00029-6

[16] E. Wikner, T. Thiringer: Extending Battery Lifetime by Avoiding High SOC. Applied Sciences 8:1825 (2018) doi:10.3390/app8101825

[17] A. Barréa, B. Deguilhem, S. Grolleau, M. Gérard, F. Suarda, D. Riu: A review on lithium-ion battery ageing mechanisms and estimations for automotive applications. Journal of Power Sources Vol. 241, pp. 680-689, 2013, https://doi.org/10.1016/j.jpowsour.2013.05.040 
[18] S. H. Choi, J. Kim, Y. S. Yoon: Self-discharge analysis of LiCoO2 for lithium batteries. Journal of Power Sources 138 (2004) pp. 283-287

[19] C. Wang, X. Zhang, A. J. Appleby, X. Chen, F. E. Little: Self-discharge of secondary lithium-ion graphite anodes. Journal of Power Sources 112 (2002) pp. 98-104

[20] Steven E. Sloop, John B. Kerr, Kim Kinoshita: The role of Li-ion battery electrolyte reactivity in performance decline and self-discharge. Journal of Power Sources 119-121 (2003) pp. 330-337

[21] Ramaraja P. Ramasamy, Jong-Won Lee, Branko N. Popov: Simulation of capacity loss in carbon electrode for lithium-ion cells during storage. Journal of Power Sources 166 (2007) pp. 266-272

[22] Z. Mao, M. Farkhondeh, M. Pritzker, M. Fowler, Z. Chen: Calendar Aging and Gas Generation in Commercial Graphite/NMC-LMO Lithium-Ion Pouch Cell. Journal of The Electrochemical Society, 164 (14) A3469A3483 (2017). DOI: 10.1149/2.0241714jes

[23] M. A. Sörés and B. Hartmann, Overview of possible methods of determining self-discharge, 2020 IEEE International Conference on Environment and Electrical Engineering and 2020 IEEE Industrial and Commercial Power Systems Europe (EEEIC / I\&CPS Europe), Madrid, Spain, 2020, pp. 1-5, doi: 10.1109/EEEIC/ICPSEurope49358.2020. 9160787

[24] N. E. Galushkin, N. N. Yazvinskaya, D. N. Galushkin, Generalized model for self-discharge processes in alkaline batteries, J. Electrochem. Soc. 159 (8) (2012) A1315-A1317

[25] Thomas Deutschen, Sophie Gasser, Manuel Schaller, Jochen Siehr: Modeling the self-discharge by voltage decay of a NMC/graphite lithiumion cell. Journal of Energy Storage 19 (2018) 113-119

[26] J. Yang, C. Du, T. Wang, Y. Gao, X. Cheng, P. Zuo, Y. Ma, J. Wang, G. Yin, J. Xie, B. Lei: Rapid Prediction of the Open-Circuit-Voltage of Lithium Ion Batteries Based on an Effective Voltage Relaxation Model. Energies 2018, 11, 3444; doi:10.3390/en11123444

[27] A. Kumar, A. Biswas: Techno-Economic Optimization of a Stand-alone PV/PHS/Battery Systems for very low load Situation. International Journal of Renewable Energy Research. Vol. 7, No. 2, pp. 844-856, 2017

[28] https://datasheetspdf.com/pdf-file/1160668/Panasonic/UR18650NSX/1 (accessed 2020.12.07)

[29] M. Petzl and M. A. Danzer, Advancements in OCV Measurement and Analysis for Lithium-Ion Batteries, in IEEE Transactions on Energy Conversion, Vol. 28, No. 3, pp. 675-681, Sept. 2013, doi: 10.1109/TEC.2013.2259490 
[30] S. Abu-Sharkh, D. Doerffel: Rapid test and non-linear model characterisation of solid-state lithium-ion batteries. Journal of Power Sources Vol. 130, pp. 266-274, 2004

[31] Y. Zheng, M. Ouyang, X. Hanb, L. Lub, J. Lib: Investigating the error sources of the online state of charge estimation methods for lithium-ion batteries in electric vehicles. Journal of Power Sources Vol. 377, pp. 161188. 2018

[32] H. Wenzl, Batteries and fuel cells, Efficiency, Encyclopedia of Electrochemical. Power Sources, Elsevier, Amsterdam, 2009, pp. 544-551

[33] Balazs Gyenes, D. A. Stevens,V. L. Chevrier, J. R. Dahn: Understanding Anomalous Behavior in Coulombic Efficiency Measurements on Li-Ion Batteries

[34] M. Lewerenz, J. Münnix, J. Schmalstieg, S. Kabitz, M. Knips, Dirk Uwe Sauer: Systematic aging of commercial LiFePO4|Graphite cylindrical cells including a theory explaining rise of capacity during aging. Journal of Power Sources. Vol. 345, pp. 254-263, 2017

[35] B. V. Rajanna, M. K. Kumar: Comparison of one and two time constant models for lithium ion battery. International Journal of Electrical and Computer Engineering Vol, 10, No. 1, pp. 670-680, 2020

[36] M. Messing, T. Shoa and S. Habibi: Lithium-Ion Battery Relaxation Effects. 2019 IEEE Transportation Electrification Conference and Expo (ITEC), pp. 1-6, doi: 10.1109/ITEC.2019.8790449, 2019

[37] https://bitbucket.org/milansores93/dataset_sd_soh/src/main/Measurement_ data.xlsx (accsessed 2021.08.10) 